Original Contribution

\title{
MEAT COLOUR CHARACTERISTICS OF DIFFERENT PRODUCTIVE TYPES DOMESTIC QUAILS
}

\author{
H. Lukanov* \\ Faculty of Agriculture, Trakia University, Stara Zagora, Bulgaria
}

\begin{abstract}
The aim of the present study was to investigate the meat colour characteristics, using CIE L*a*b* colour description system, of quails from the two main production types reared in Europe: the intermediate heavy (dual-purpose) and heavy (meat-type). Quails were separated by gender in male and female subgroups, as follows: Am, Af, Dm, Df, Mm and Mf, where A group was dual-purpose and D and M groups were from heavy type. Meat colour characteristics of the breast (M. pectoralis superficialis), tenders (M. pectoralis profundus) and leg muscles (M. Iliotibialis lateralis pars postacetabularis) were evaluated on post mortem hour 24 in CIE L*a*b* colour description system. On the basis of L*, a* and $\mathrm{b}^{*}$ values, the chroma $\left(\mathrm{C}^{*}\right)$, colour index $(\mathrm{CI})$ and meat colour index (MCI) were calculated. The lateral surface of $M$. p. superficialis was substantially darker in the light all-purpose type than in the heavy group $\mathrm{M}(\mathrm{p}<0.001)$. The lowest lightness values $\left(\mathrm{L}^{*}\right)$ were detected on $M$. p. superficialis facies medialis and the outer surface of $M . p$. profundus. The highest average meat redness was detected on $M$. $p$. superficialis facies medialis and the lowest - in thigh muscles (M. iliotibialis). Average yellowness (b*) of all studied muscles were positive in all groups of quails, with statistically significantly lower values in females vs males. The sex-related analysis showed that indices CI and MCI were considerably lower for both surfaces of $M$. p. superficialis in subgroup Am than in subgroups Dm and $\mathrm{Mm}(\mathrm{p}<0.001)$. Similar differences were found out for the thigh muscle $(\mathrm{p}<0.05)$.
\end{abstract}

Key words: Japanese quail, meat production, meat quality, CIELab, meat colour index

\section{INTRODUCTION}

Domesticate Japanese quails is the smallest from all poultry species, their live weight varies from $120-140$ to $400-450 \mathrm{~g}$. They have very good production potential, both for eggs and for meat. The egg laying capacity is comparable with that of domestic chicken. The heavy type of quails has excellent fattening features and dietetic meat. Quails matured on the 35-42 days of age, which made them the earliest maturing domestic animal (1). This short generation interval is the main reason for the fast selection progress in this species.

The market segmentation has formed three main types of domestic quails - light type (egg-laying), intermediate (combined or dual-

*Correspondence to: Hristo Lukanov, PhD; Department of Animal Science - monogastric and other animals, Faculty of Agriculture, Trakia University,6000 Stara Zagora, Bulgaria, e-mail: dr_lukanov@abv.bg, telephone: +359/ 898 419751. purpose) and heavy (meat-type). Nowadays, light type quails are reared in East Asia for egg production. In the other parts of the world, stock eggs are produced with the heavier dualpurpose type which allows production of meat with satisfactory slaughter quality from male birds. The quails from the heavy type are predominantly used for production of highquality quail meat, and eggs are mainly used for breeding (2).

Appearance and texture of poultry meat are the two most important quality attributes (3). Appearance (skin colour, meat colour, cooked meat pinkness, and appearance defects) is of particular importance for buyer choice. Meat colour is one of primary factors with effect on consumer's attitudes $(4,5)$. There are numerous factors that affect poultry meat colour - species, age, breed, environmental factors, processing practices, stress, etc $(3,4$, $6)$. 
The aim of the present study was to investigate the meat colour characteristics, using CIE $\mathrm{L} * \mathrm{a} * \mathrm{~b} *$ colour description system, of quails from the two main production types in Europe: the intermediate heavy (dual-purpose) and heavy (meat-type).

\section{MATERIAL AND METHODS}

The study was carried out in the Experimental base of the Poultry Breeding Unit, Department of Animal Science - monogastric and other animals, Faculty of Agriculture, Trakia University - Bulgaria. Japanese quails from two productive types were used: the intermediate heavy (dual-purpose) and heavy (meat-type). The birds from the dual-purpose type originated from a stock farm for quail eggs production (Group A). The heavy type quails comprised two genotypes: a German broiler line with wild-type plumage colour (Group D) and population GG selected in the Poultry Breeding Unit, Department of Animal Science - monogastric and other animals, Faculty of Agriculture, with golden plumage (group M). They were separated by gender on the male and female subgroups, as follows: Am, Af, Dm, Df, Mm and Mf.

Quails were reared in cages according to animal hygiene requirements of the species. Up to 14 days of age, they received starter feed; between 15-21 days of age: grower and from 22 to 35 days of age - finisher. The nutritional value of feeds was:

Starter (1-14 days of age)

Metabolisable energy: $12.0 \mathrm{MJ} / \mathrm{kg}$; Crude protein: $23.9 \%$; Crude fibre: $4.21 \%$; Calcium: 1.0\%; Available phosphorus: $0.46 \%$; Lysine: 1.45\% ; Methionine: $0.46 \%$ and Methionine + cysteine: $0.78 \%$;

Grower (15-21 days of age)

Metabolisable energy: $12.1 \mathrm{MJ} / \mathrm{kg}$; Crude protein: $21.0 \%$; Crude fibre: $4.67 \%$; Calcium: 1.1\%; Available phosphorus: $0.45 \%$; Lysine: 1.15\%; Methionine: $0.5 \%$ and Methionine + cysteine: $0.85 \%$;

Finisher (22-35 days of age)

Metabolisable energy: $12.4 \mathrm{MJ} / \mathrm{kg}$; Crude protein: $18.1 \%$; Crude fibre: $4.42 \%$; Calcium: 1.0\%; Available phosphorus: $0.41 \%$; Lysine: 1.0\%; Methionine: $0.43 \%$ and Methionine + cysteine: $0.75 \%$;

The meat colour analysis were done in the laboratory of the Poultry Breeding Unit, Faculty of Agriculture, Trakia University, Bulgaria. 12 birds from all six subgroups (Am,
LUKANOV H.

Af, Dm, Df, Mm and Mf) with weight average for the group were selected. Meat colour characteristics, being among the most important traits for consumers, were evaluated on post mortem hour 24 by means of PCECSM 2 spectrophotometer. The most valuable meat parts were analysed: the breast $(M$. pectoralis superficialis), tenders (M. pectoralis profundus) and leg or ITL muscle (M. Iliotibialis lateralis pars postacetabularis). During meat colour analysis, CIE L*a*b* coordinates (7) were determined in D65 illuminant. $M$. pectoralis superficialis was evaluated on lateral and medial muscle surfaces. Colour of $M$. pectoralis profundus was measured on lateral surface. The muscle with most convenient location and sufficient surface for meat colorimetry in Japanese quails was $\quad M$. Iliotibialis lateralis (pars postacetabularis) which hereinafter for convenience will be called $M$. iliotibialis or ITL muscle. The colour of the ITL muscle was determined in the central lateral area. On the basis of $a^{*}$ and $b^{*}$ values, the chroma $\left(C^{*}\right)$, colour index $(\mathrm{CI})$ and meat colour index (MCI) were calculated using the formulas:

Chroma $C^{*}=\left(a^{* \wedge} 2+b^{* \wedge} 2\right)^{\wedge} 0.5$ [1] (8);

Colour index (Shell Color Index) $\mathrm{CI}=\mathrm{L}^{*}-\mathrm{a}^{*}$ $-b^{*}$ [2] (9), where lower values corresponded to darker meat colour;

Meat colour index $(\mathrm{MCI})=\mathrm{L}^{*}-\mathrm{C}^{*}[3](10)$.

All data were analysed with Statistica 13.0 software (Statistica for Windows; Stat - Soft, 2015). Mean (x), standard error of mean (SEM) and coefficient of variation $(\mathrm{CV}, \%)$ values were calculated for each group and subgroup. The differences considered statistically significant at $\mathrm{p}<0.05$, using Student's t-test, if the data were normally distributed.

\section{RESULTS AND DISCUSSION}

The colour of quail meat is most frequently detected on the lateral surface of $M . p$. superficialis. Quail meat is darker than that of popular domestic poultry species - chickens, turkeys, ducks, thus it belong to the so-called game type meats. Figures 1, 2 and 3 present visually between-subgroup differences in values of $\mathrm{L}^{*}, \mathrm{a}^{*}$ and $\mathrm{b}^{*}$ coordinates in the three measured muscles with comparison of data for both sexes.

In a previous study, $\mathrm{L}^{*}$ values increased the most dramatically during the first 24 hours post mortem (11). Average lightness of meat 
( $\mathrm{L}^{*}$ coordinate) showed the highest values e.g. lightest colour of the lateral M. p. superficialis surface. The average values of the trait in the different subgroups varied from $47.6 \pm 0.31$ in subgroup Af to $53.33 \pm 0.32$ in subgroup Mf. The lateral surface of the major breast muscle was statistically significantly darker in the light all-purpose type than that of the heavy type $M$ $(p<0.001)$. Similar results were reported also by Choi et al. (12). The comparison between the sexes demonstrated a considerable difference only in males, where average values
LUKANOV H.

in subgroup Am were statistically significantly lower than those in subgroups Dm and $\mathrm{Mm}$ $(\mathrm{p}<0.001)$. Wilkanowska and Kokoszynski (13) reported higher values than presented in this study for lightness of the superficial pectoral muscle in 33-day-old Pharaoh quails by the $30^{\text {th }}$ minute post mortem. The analysis of 42-day-old quails gave similar to our results. Comparable lightness values of the outer surface of $M$. p. superficialis were given by Genchev et al. (14) and Vargas-Sánchez et al. (15).

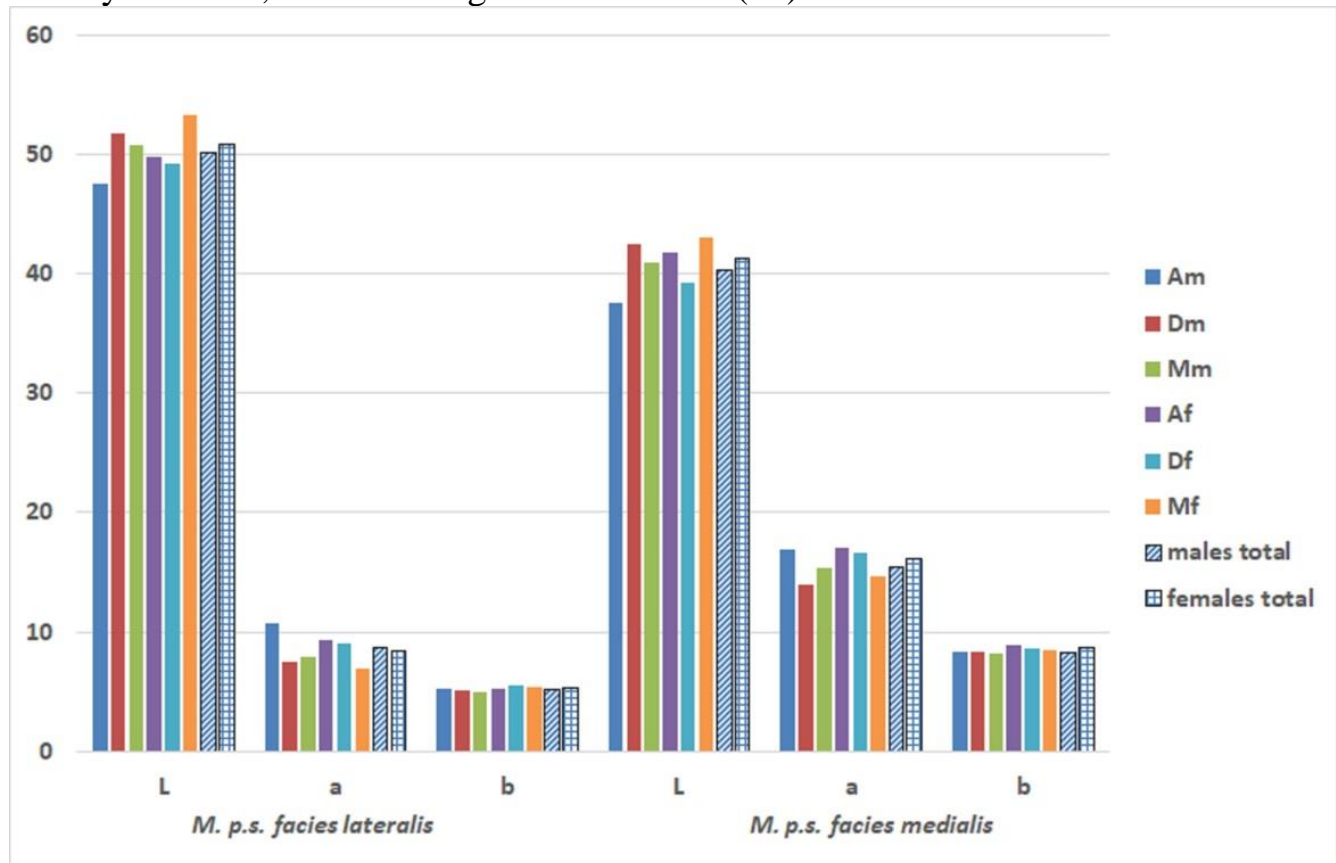

Figure 1. Average values of $\mathrm{L}^{*}, \mathrm{a}^{*}$ and $\mathrm{b}^{*}$ of $M . p$. superficialis in the six subgroups of quails and in sex-related data in all quails.

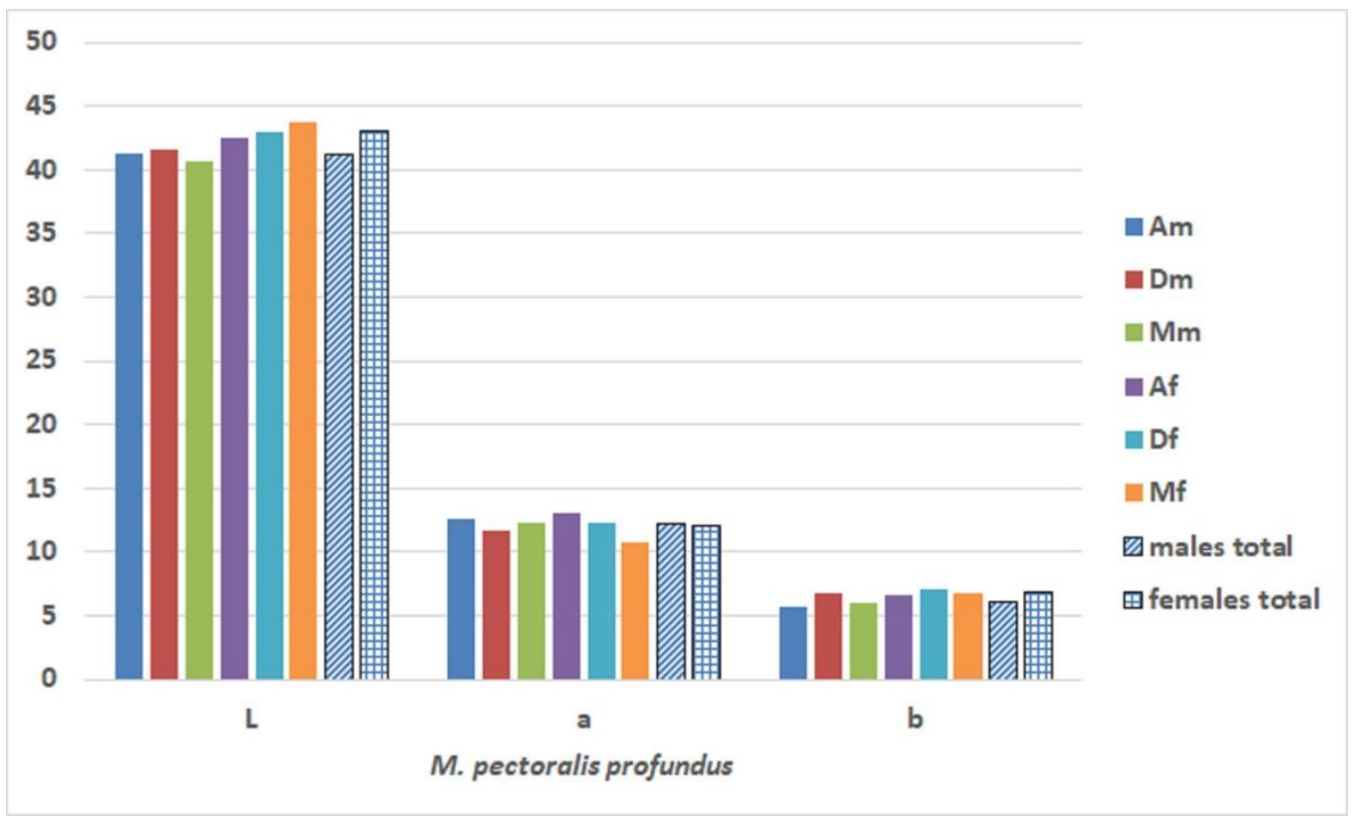

Figure 2. Average values of $\mathrm{L}^{*}, \mathrm{a}^{*}$ and $\mathrm{b}^{*}$ of $M$. p. profundus in the six subgroups of quails and in sex-related data in all quails. 


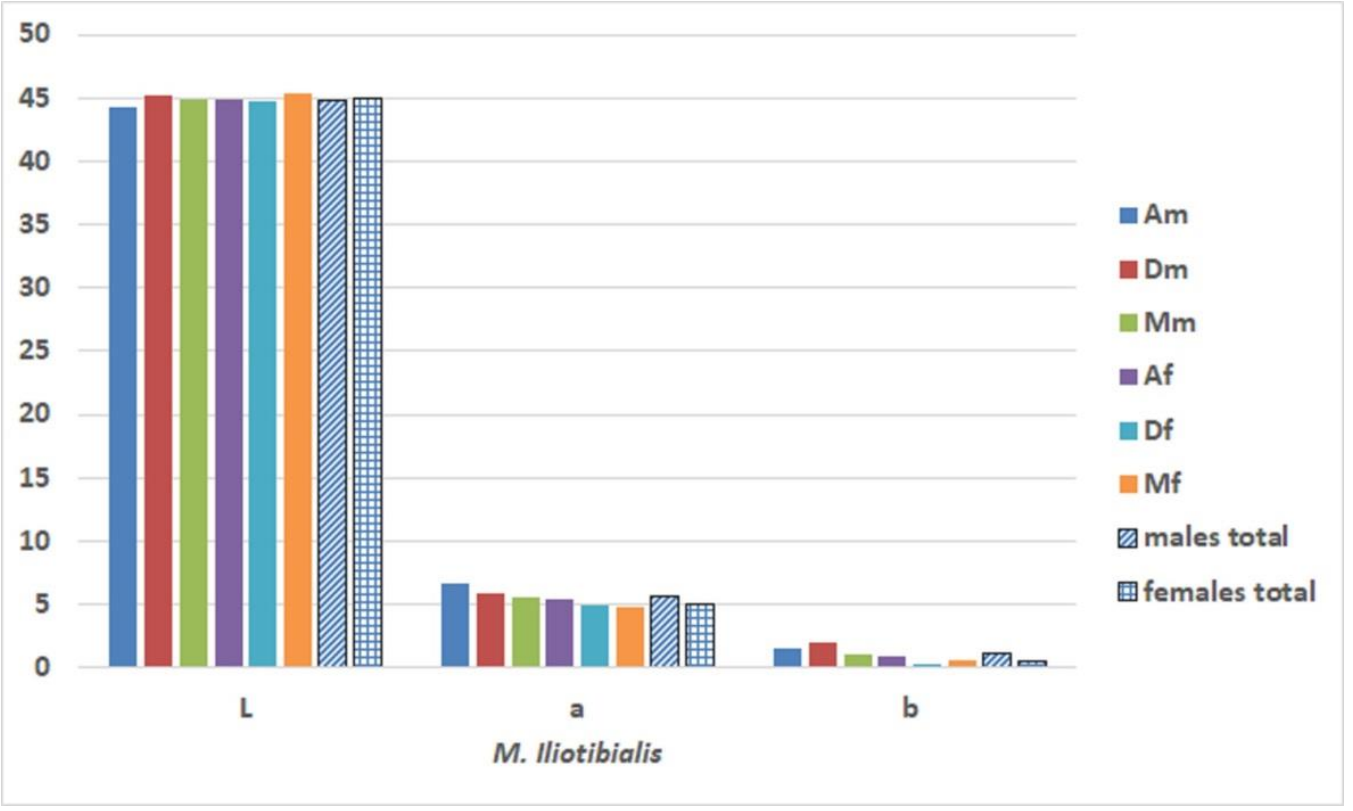

Figure 3. Average values of $\mathrm{L}^{*}, \mathrm{a}^{*}$ and $\mathrm{b}^{*}$ of $M$. iliotibialis in the six subgroups of quails and in sex-related data in all quails.

The next zone with highest lightness in descending order was the outer surface of $M$. iliotibialis. Average lightness of this zone were slightly lower than those in $M$. p. superficialis facies lateralis and varied from $44.24 \pm 0.31$ in subgroup Am to $45.42 \pm 0.26$ in subgroup Mf. Unlike the pectoral muscle, this zone showed much lower between-group variation. The muscle also tended to be darker in group A compared to group $M$ with insignificant differences. Similar comparison between sexes showed that male birds from the dual-purpose type (subgroup Am) showed slightly lower lightness than males from heavy subgroups Dm and $\mathrm{Mm}$.

The lowest lightness values were measured on the inner surface of $M$. p. superficialis facies medialis and the outer surface of $M . p$. profundus. Greater between-subgroup variation of the trait was observed in the former muscle with average $L^{*}$ from $37.57 \pm 0.4$ in subgroup Am to $43.03 \pm 0.65$ in subgroup Mf. Similarly to aforementioned muscle zones, the present ones were darker in males from subgroup Am than in subgroups Dm and $\mathrm{Mm}(\mathrm{p}<0.001)$. This tendency was absent only for $M$. p. profundus. Tarasewicz et al. (16) affirmed comparable but lower values of the trait in 42-day-old Pharaoh quails. On the contrary, Narinc et al. (17) reported slightly higher values in 35-day-old quails. Ribarski and Genchev (18) observed significantly higher average lightness of muscles in Pharaoh and Manchurian Golden quails as compared both to present results and those of other researchers.

The between-sex differences of breast meat lightness in Japanese quails $\left(\mathrm{L}^{*}\right)$ allowed concluding that male birds at 5 weeks of age had statistically significantly darker meat than females at the same age (Figures 1 and 2; $\mathrm{p}<0.001)$. Similar trend was present with respect to thigh muscles too (Figure 3).

The a* coordinate in the CIE L*a*b* system includes the red-green spectrum, therefore its positive values are red, and negative ones green. The $\mathrm{a}^{*}$ values of the four measured muscle zones were positive. The highest average values of redness $\left(\mathrm{a}^{*}\right)$ were found out on the M. p. superficialis facies medialis from $13.92 \pm 0.37$ in subgroup $\mathrm{Dm}$ to $16.98 \pm 0.33$ in subgroup Af, which were lower than those reported by Narinc et al. (17) and Ribarski and Genchev (18). Comparable but lower redness values were established for tenders with range from $10.79 \pm 0.32$ in $\mathrm{Mf}$ and $13.07 \pm 0.44$ in subgroup Af. These values were somewhat lower than those of Ribarski and Genchev (18). The lowest values of the trait were measured in thigh muscle (M. iliotibialis) with variation from $4.78 \pm 0.07$ (subgroup Mf) to $6.59 \pm 0,13$ (subgroup Am).

Redness of the outer and inner surface of the major pectoral muscle was statistically significantly higher in the dual-prpose light type as compared to the heavy type. A similar 
tendency was found for redness values of the other muscle zones. Male quails exhibited higher meat redness than females in almost all studied zones, except for $M$. p. superficialis facies medialis (Figures 1, 2 and 3). In their colorimetric research in one meat-type and two egg-type lines of Japanese quails, Fuzinatto et al. (19) did not report any difference in colour characteristics between the types.

The coordinate $b^{*}$ could be positive or negative and characterises respectively the yellow-green spectrum. The highest average meat yellowness $\left(\mathrm{b}^{*}\right)$ was demonstrated for $M$. p. superficialis facies medialis with slight between-subgroup variation (from $8.96 \pm 0.17$ to $8.16 \pm 0.21$ ). Similar although higher average $\mathrm{b}^{*}$ values were presented by Tarasewicz et al. (16) and Ribarski and Genchev (18) in meat-
LUKANOV H.

type quails. Other authors reported slightly lower values of the trait in fattening quails (14, 17). The thigh muscles (M. iliotibialis) of all quails were outlined with the lowest $b^{*}$ values with both positive or negative sign with individual values from -2.94 to 4.92 . Average yellowness values were positive, with substantially lower values on females than in males (Figure 3). Breast muscles exhibited the opposite tendency - higher $\mathrm{b}^{*}$ values in females compared to males (Figures 1 and 2).

Figures 4 and 5 present $\mathrm{CI}$ and MCI on lateral and medial surfaces of $M$. p. superficialis, the deep pectoral muscle (M. p. profundus) and the thigh muscle (M. iliotibialis). The values were also grouped according to the sex, similarly to previous figures.

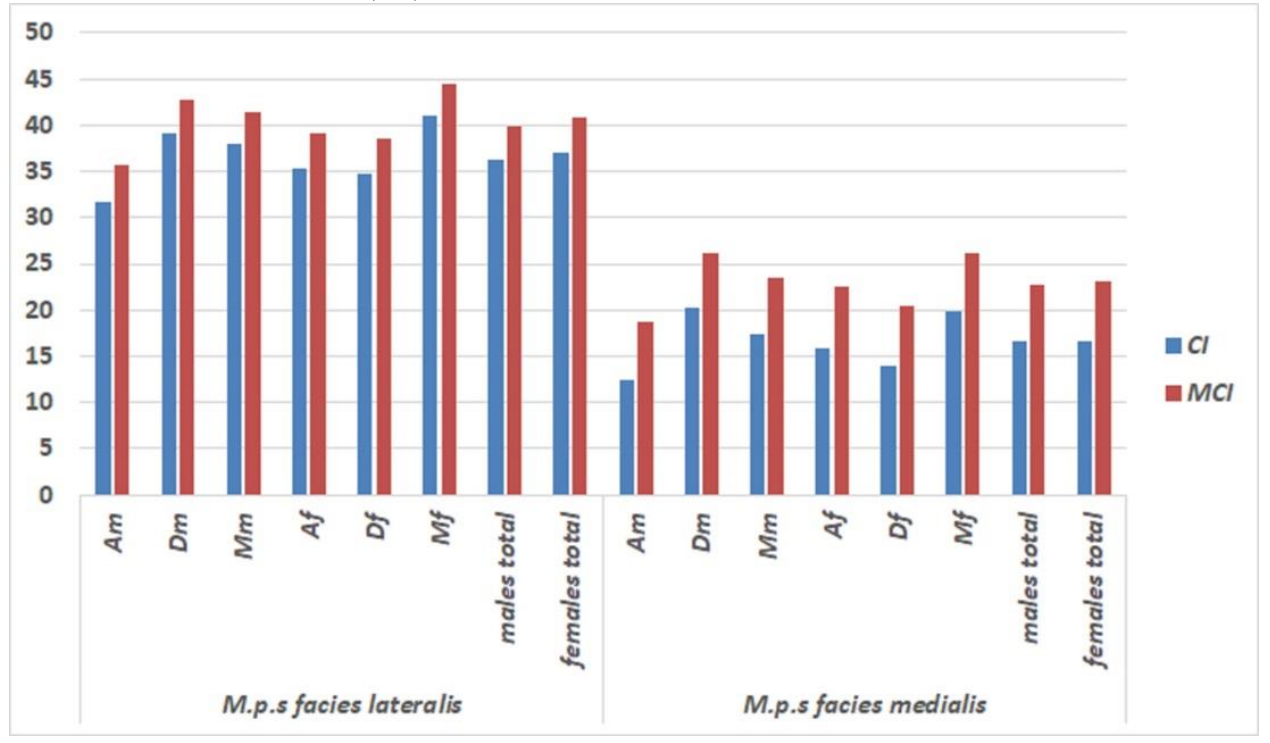

Figure 4. Colour index (CI) and meat colour index (MCI) of M. p. superficialis in the six subgroups of quails and in sex-related data in all Japanese quails.

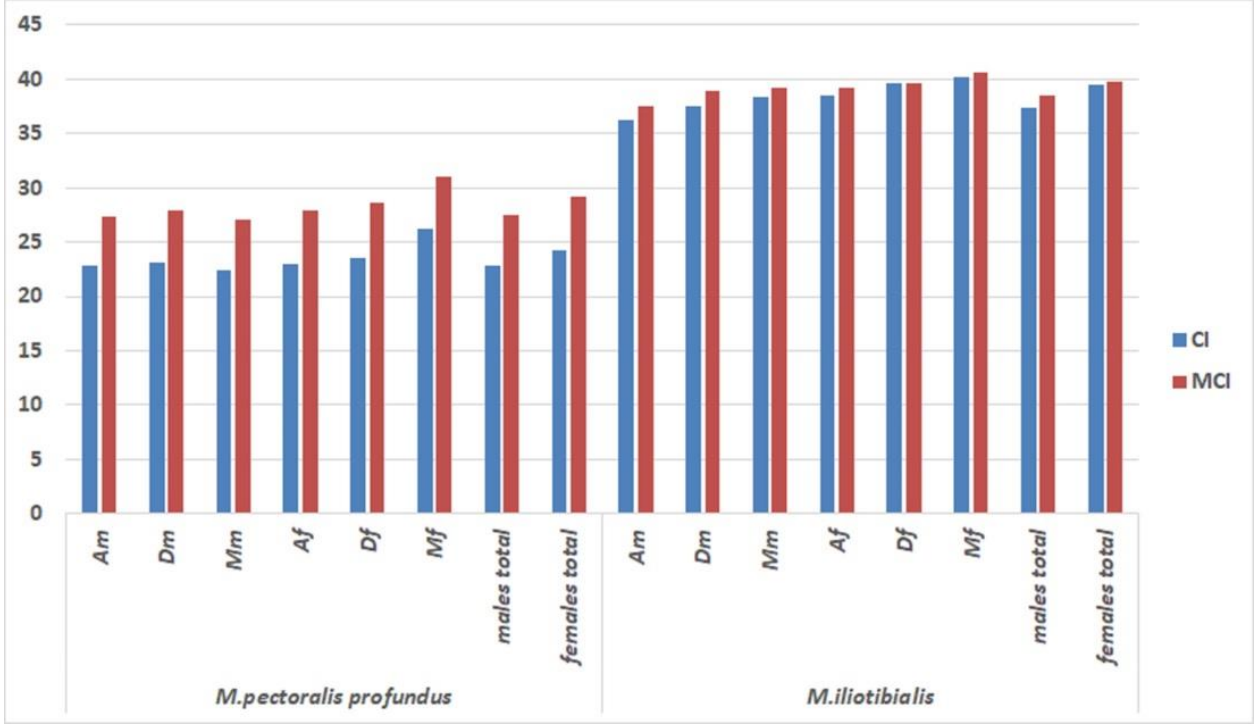

Figure 5. Colour index (CI) and meat colour index (MCI) of M. p. profundus and M. iliotibialis in the six subgroups of quails and in sex-related data in all Japanese quail. 
The chroma $\left(\mathrm{C}^{*}\right)$ reflects the interaction between both colour coordinates $-a^{*}$ and $b^{*}$. Logically, the highest chroma values were observed on muscle with highest $\mathrm{a}^{*}$ and $\mathrm{b}^{*}$ values $-M$. p. superficialis facies medialis. The lowest $\mathrm{C}^{*}$ values were found out in $M$. iliotibialis. It could be therefore inferred that the meat of the light dual-purpose type of quails (group A), had statistically significantly higher chroma values $\left(C^{*}, p<0.05\right)$ than meat produced from the heavy types (groups $\mathrm{D}$ and M).

The colour index (CI) has been used for evaluation of the eggshell colour (9) and applied in a study on salt-cured quail meat (20). It is based on the three CIE L*a*b* coordinates. In a study of ours, a colour index (MCI) appropriate for evaluaiton of meat was proposed (10). Similarly to CI, it is also based on the three CIE $\mathrm{L}^{*} \mathrm{a}^{*} \mathrm{~b}^{*}$ coordinates but chroma $\left(\mathrm{C}^{*}\right)$ presents the coordinates $\mathrm{a}^{*}$ and $\mathrm{b}^{*}$. That is why the MCI has higher values than the original index of Cavero et al. (9), attributing a smaller importance to ligthness $\left(\mathrm{L}^{*}\right)$. The lower the $\mathrm{a}^{*}$ and $\mathrm{b}^{*}$ values and the differences between them, the closer values of both indices will be obtained. Similar close values of $\mathrm{CI}$ and $\mathrm{MCI}$ were obtained for thigh muscle (M. iliotibialis). Regardless of the close values of the two indices, CI remains lower than MCI.

The light all-purpose type (group A) showed statistically significantly lower values of boneless breast colour indices (inner and outer surfaces) compared to group $M$ from the heavy quail type $(p<0.001)$. The analysis of data by sexes showed considerably lower CI and MCI values of both surfaces of $M$. p. superficialis in subgroup Am vs subgroups Dm and $\mathrm{Mm}$ $(p<0.001)$. Similar statistical differences were found out for the thigh muscle $(p<0.05)$. The highest values of the colour indices were detected on the lateral surfaces of $M . p$. superficialis and $M$. iliotibialis. They could be explained with the high $\mathrm{L}^{*}$ and low $\mathrm{a}^{*}$ and $\mathrm{b}^{*}$ values in these zones. The lowest $\mathrm{CI}$ and MCI values were found out on the medial $M . p$. superficialis surface, which exhibited higher positive $a^{*}$ and $b^{*}$ values compared to tenders. Average MCI values of $M$. p. superficialis facies medialis varied from $35.64 \pm 0.63$ in subgroup Am to $44.52 \pm 0.48$ in subgroup Df. Male quails had statistically significantly lower values of the trait than females $(p<0.05)$. Totally opposite results were demonstrated for MCI of the inner $M$. p. superficialis surface.
The minimum average values were those of subgroup Am - $18.74 \pm 0.59$, and the maximum: in subgroup Dm - 26.22 \pm 0.87 . The difference was not statistically significant but higher in females $(p>0.05)$. Unlike both surfaces of $M$. p. superficialis, the tenders and $M$. iliotibialis did not show any big betweensubgroup differences with respect to MCI. The MCI range for $M$. p. profundus was 4.01, and for M. iliotibialis - 3.1 points. For both muscles, statistically significantly higher MCI was found out in females than in males $(\mathrm{p}<0.05)$, as illustrated on Figure 5.

\section{CONCLUSION}

The results of the present study suggest that there are some differences in meat colour characteristics, influenced by production type and gender of the Japanese quails.

Both indexes ( $\mathrm{CI}$ and $\mathrm{MCI}$ ) could be used for meat colour expression, where the MCI has higher values than the CI, attributing a smaller importance to ligthness $\left(\mathrm{L}^{*}\right)$.

\section{REFERENCES}

1. Lukanov, H., Genchev, A. and Kolev, P., Comparative investigation of egg production in WG, GG and GL Japanese quail populations. Trakia Journal of Sciences, 4: 334-343, 2018.

2. Genchev, A. and Lukanov, H., Padpadakovadstvo. Stara Zagora, 2018, In Print. (In Bulgarian)

3. Fletcher, D.L., Poultry meat quality. World's Poultry Science Journal, 58: 131145, 2002.

4. Mugler, D.J. and Cunningham. F.E., Factors affecting poultry meat color-A Review*. World's Poultry Science Journal, 28 (4): 400-406, 1972.

5. Manchini, R.A. and Hunt, M.C., Current research in meat color. Meat Science, 71 (1): 100-121, 2005.

6. Froning, G.W., Color of poultry meat. Poultry and Avian Biology Reviews, 6(1): 83-93, 1995.

7. C.I.E. Compagnie Internationale de l'Eclairage. International Commission on Illumination, Recommendations on uniform color spaces. Supplement No. 2 to CIE publication No. 15.2, Bureau central, Paris. 1978.

8. Petracci, M. and Baeza, E., Harmonization of methodology of assessment of poultry meat quality features. Working paper of WPSA, Working Group 5 Poultry Meat, 1$18,2009$. 
9. Cavero, D., Schmutz, M., Icken, W. and Preisinger, R., Attractive eggshell color as a breeding goal. Lohmann Information, 47 (2): 15-21, 2012.

10.Lukanov, H., Genchev, A., Penchev, I. and Penkov, D., Meat composition and quality in male Japanese quails from heavy Pharaoh line. Trakia Journal of Sciences, 4:327-333, 2018.

11. Vasileva, P., Lukanov, H. and Genchev, A., Meat quality traits in Japanese quails with regard to storage conditions and duration. Agricultural Science and Technology, 6 (4): 475-479, 2014.

12.Choi, Y.M., Hwang, S. and Lee, K., Comparison of muscle fiber and meat quality characteristics in different Japanese quail lines. Asian-Australasian Journal of Animal Sciences, 29 (9): 1331-1337, 2016.

13.Wilkanowska, A. and Kokoszyński, D., Comparison of slaughter value in Pharaoh quail of different ages. Journal of Central European Agriculture, 12 (1): 145-154, 2011.

14.Genchev, A., Michavlov, G., Ribanski, S., Pavlov, A. and Kabakchiev, M., Meat quality and composition in Japanese quails. Trakia Journal of Sciences, 6:72-82, 2008.

15.Vargas-Sánchez, R.D., Torrescano-Urrutia, G.R., Ibarra-Arias, F.J., Portillo-Loera, J.J., Ríos-Rincón, F.G. and Sánchez-Escalante, A., Effect of dietary supplementation with
LUKANOV H.

Pleurotus ostreatus on growth performance and meat quality of Japanese quail. Livestock Science, 207: 117-125, 2018.

16.Tarasewicz, Z., Gardzielewska, J., Szczerbińska, D., Ligocki, M., Jakubowska, M. and Majewska, D., The effect of feeding with low-protein feed mixes on the growth and slaughter value of young male Pharaoh quails. Archiv Tierzucht, 50: 520-530, 2007.

17.Narinc, D., Aksoy, T., Karaman, E., Aygun, A., Firat, M.Z. and Uslu, M.K., Japanese quail meat quality: Characteristics, heritabilities, and genetic correlations with some slaughter traits. Poultry Science, 92 (7): 1735-1744, 2013.

18.Ribarski, S. and Genchev, A., Effect of breed on meat quality in Japanese quails (Coturnix coturnix japonica). Trakia Journal of Sciences, 2: 181-188, 2013.

19.Fuzinatto, M.N., Menezes, L.A.A., Terres, C.M., Grieser, D.O., Zancanela, V. and Baldissera, E.M., Analysis of quail meat color: meat and laying quail breeds. Proceedings of XVI World Congress of Food Science and Technology - IUFoST, Brazil. 42148, 2012.

20.Ribarski, S., Lukanov, H., Penchev, I., Genchev, A. and Lyutskanova, E., Effects of salt-curing on physicochemical and technological properties of Japanese quail breast meat. Agricultural Science and Technology, 7 (3): 354-359, 2015. 